\title{
A COMPARISON REVIEW OF THE CLINICAL HEALTHCARE SERVICES PROVIDED TO LIVER DISEASE PATIENTS IN THE GCC
}

\author{
Maram Morizeq Alkhammash ${ }^{1,2}$, Bussma Ahmed Bugis ${ }^{1}$ \\ ${ }^{1}$ Department of Public Health College of Health Sciences, Saudi Electronic University, Saudi Arabia \\ 2 Liver Disease Research Center, Department of Medicine, College of Medicine, King Saud University, Saudi Arabia
}

Address for Correspondence: Maram Morizeq Alkhammash, E-mail: marambiochem@gmail.com

Received: 05.01.2021; Accepted: 25.03.2021; Available Online Date: 27.05.2021

(C) Copyright 2021 by Dokuz Eylül University, Institute of Health Sciences - Available online at https://dergipark.org.tr/en/pub/jbachs

Cite this article as: Alkhammash MM, Bugıs BA. A Comparison Review Of The Clinical Healthcare Services Provided To Liver Disease Patients In The GccJ Basic Clin Health Sci 2021; 2: 22-35.

\begin{abstract}
Liver diseases are a critical health concern in the Gulf Cooperation Council (GCC). Fatty liver disease and viral hepatitis are the two most common liver-disease-related health problems in the region. Hepatocellular carcinoma development adds to the burden of liver cirrhosis. Given the importance of identifying patients with liver disease, it is essential to examine the GCC's healthcare services. The goal of this study was to compare the clinical care services provided to liver disease patients in GCC member countries. A systematic comparative analysis of GCC studies from 2014 to 2020 on related topics was conducted. Articles relevant to liver disease prevalence rate, incidence, and clinical healthcare services, including mental health support, palliative care, liver surgery and transplantation, management of viral hepatitis B and $\mathrm{C}$, dental care services, HBV and pregnancy, vaccination among HCWs and national screening were included in this study. The study results showed that most of the clinical healthcare services provided to liver disease patients are available in all GCC member countries. The prevalence of communicable diseases has significantly decreased among the GCC countries, indicating that there are successful healthcare systems for tracking and controlling disease spread at the level of the GCC. The same can be said of the management of viral hepatitis in Gulf countries. Despite the similarities of clinical services provided to liver disease patients, the study concluded that there were differences in the availability of liver transplantation programs and the level of palliative care among GCC member countries.

Keywords: Liver Disease, Gulf Cooperation Council, Clinical Services, Healthcare Systems, Patients.
\end{abstract}

\section{INTRODUCTION}

The World Health Organization (WHO) characterizes a health system as "the people, institutions, and resources arranged together following established policies, to improve the health of the population they serve while responding to people's legitimate expectations and protecting them against the cost of ill health through a variety of activities whose primary intent is to improve health" (1). A health system requires manpower, funds, knowledge, supplies, transport, communications, and overall direction and advice. Furthermore, a health system needs to deliver services that are responsive and financially equitable while treating the population decently (2).

Healthcare services are provided within a healthcare system through primary, secondary, and tertiary care. Primary care traditionally refers to the initial contact providers who are prepared to address the vast majority of common situations for which patients seek care. Secondary care often refers to specialty care provided by clinicians who concentrate on one or a small number of organ systems or a particular type of 
service, such as hepatology. Tertiary care refers to care provided by an organization or facility, frequently academic or specialized healthcare centers such as trauma centers, transplantation centers, and neonatal care units, based on the services delivered (3).

A comprehensive care system allows patients access to essential clinical and nonclinical services that help with conditions directly related to patients' medical situations and procedural therapies. Hospitals offer a range of clinical services, such as diagnostic, therapeutic, rehabilitative, preventative, and palliative care (PC). Several services within the health system chain may not be included in immediate patient care but are necessary to benefit both patients and staff and to ensure the smooth operation of services. Both nonclinical and clinical services provide support to the delivery of effective patient care, which requires coordination between a large variety of healthcare providers and support staff. Nonclinical services strive to assist each patient holistically, not only to treat diseases, and include social worker assistance, health education and clinical nutrition services.

There are two types of diseases: communicable diseases and noncommunicable diseases (NCDs). NCDs are conditions or illnesses that are usually chronic in nature (with a slow beginning and a long progression), and for which there are no known causative agents. NCDs are not transmitted from person to person but result from genetic and lifestyle factors. NCDs represent a wide range of conditions: from cardiovascular disease, liver disease (cirrhosis and non-alcoholic fatty liver disease NAFLD), and cancers to Alzheimer's disease, chronic arthritis, and depression. Together, NCDs are the causes of the majority of deaths in the majority of countries. The impact of NCDs on mortality, however, is only one of their consequences on people's lives. Chronic diseases, mostly NCDs, are also now the most rapidly rising causes of morbidity in most developing and developed countries. As populations age, NCDs increase in frequency. The existence of two or more chronic diseases makes disability development particularly likely. The rapidly growing pattern of disability due to NCDs has substantial economic implications. The significant increase in indirect expenses for health care and the raising demand for healthcare services are partly due to the increasing burden imposed by NCDs, as well as the immense population growth and the increasing life expectancy (3).
For several centuries, communicable diseases were the leading cause of death and disability among all ages, including young and old patients. Communicable diseases are transmitted from person to person. Some examples of such diseases are influenza, mumps, chickenpox, and hepatitis B and C. Communicable diseases are the reasons for epidemics, but they can also become endemic and regularly exist and can become frequent causes of death (3). Such diseases, along with NCDs, play a critical role in maternal deaths associated with childbirth, infant deaths, and early childhood deaths, as well as the deaths malnourished newborns and children.

The prevention and management of emerging, reemerging, and stable infectious diseases is a continuous process. Preventing such diseases will prevent a spike in health expenses by reducing the number of medications that will be used in the future. Communicable diseases can be successfully monitored and controlled by adopting adequate supervision, research, and drug development strategies and by introducing countermeasures such as surveillance, diagnosis, and effective, affordable drugs and vaccines.

In studies on communicable diseases and NCDs, Asrani and colleagues found that liver disease accounts for approximately two million deaths worldwide per year, including one million deaths from cirrhosis complications and one million deaths from viral hepatitis and Hepatocellular Carcinoma (HCC) (4). Cirrhosis has recently become the 11th most common cause of death worldwide, and liver cancer is the $16^{\text {th }}$ most common causes of deaths worldwide; together, these diseases account for $3.5 \%$ of all deaths worldwide. Cirrhosis also ranks among the top 20 reasons for years of life with disability and years of life lost due to disability, accounting for $1.6 \%$ and $2.1 \%$ of the global burden, respectively. In addition, approximately two billion adults are obese or overweight, and more than $\mathbf{4 0 0}$ million have diabetes, both of which are risk factors for NAFLD and HCC. The global prevalence of viral hepatitis remains, elevated and the cases of liver damage resulting from the prolonged use of some drugs continue to increase, making such factors the leading cause of acute hepatitis at present. Liver transplantation is the second most common solid-organ transplantation, but at the current rates, fewer than $10 \%$ of global liver transplantation needs are met. These figures are quite sobering, but they emphasize a crucial 
opportunity to promote public health given that most cases of liver disease are preventable (4).

Geographically, the Gulf Cooperation Council (GCC) consists of six countries as member states: Bahrain, Kuwait, Oman, Qatar, Saudi Arabia, and the United Arab Emirates (UAE). In GCC member countries, treatment expenses incurred abroad are generally reimbursed by the healthcare authorities and other government agencies. The health services in the GCC are delivered free of charge to all citizens, and health insurance is available for both expatriates and nationals. In GCC member countries, however, the cases of different cancers, including liver cancer, are increasing.

Liver cirrhosis may lead to HCC, and the leading causes of liver cirrhosis and progression toward HCC are chronic hepatitis B (CHB) and C. In GCC member countries with substantially young populations, the burden of NAFLD and associated liver diseases may each very elevated levels, suggesting potentially ower rates of advanced liver disease in the near term and potentially significant increases in disease burden in the coming decades. Liver diseases exhibit variability in their prevalence, incidence, and mortality patterns and in the pattern of the ultimate burden that they impose (5). Thus, while identifying liver disease patients is important, assessing healthcare services in GCC member countries is also necessary. This study reviews clinical healthcare services available in GCC member countries as published in the literature because the management of liver disease patients in such countries is mostly clinical in nature.

\section{Current Status of Liver Disease Patients in GCC}

Liver diseases are a significant health issue in GCC member countries. Specifically, fatty liver disease and viral hepatitis are the two most common health problems related to liver disease, and the development of liver cirrhosis and HCC adds to the burden imposed by such diseases.

\section{Fatty Liver Disease Prevalence}

NAFLD is characterized by a cytoplasmic accumulation of fat in more than $5 \%$ of the hepatocytes with or without inflammation when steatosis caused by excessive consumption of alcohol, viral hepatitis, genetic abnormalities, and drugs is excluded. NAFLD includes a variety of histological abnormalities. The mildest phase, nonalcoholic fatty liver (NAFL), is characterized by simple steatosis without inflammation, fibrosis, or hepatocyte balloon degeneration. NAFL rarely advances into cirrhosis. Non-alcoholic steatohepatitis (NASH) is a more severe type of NAFLD characterized by balloon degeneration and lobular inflammation accompanying steatosis. NASH progresses to cirrhosis in $40 \%$ of patients (6). As NAFLD is the hepatic component of the metabolic syndrome, its prevalence parallels those of type 2 diabetes mellitus and obesity. Consequently, overnutrition and a sedentary lifestyle are the main risk factors for NAFLD, but as there are essential interethnic variations in the susceptibility to NAFLD, it may also be associated with genetic characteristics (7).

Al Hammadi and Reilly reported that in the GCC the incidence of obesity among schoolchildren and adolescents ranges from $25 \%$ to $30 \%$. Overweight and obese children are more likely to remain obese into adulthood and thus to encounter problems associated with obesity (8). These alarming statistics indicate a likely increase in NAFLD morbidity, which may lead to NASH. A recent study by Alswat and colleagues revealed that NAFLD's overall prevalence rate was estimated to be $25.7 \%$ in Saudi Arabia and $25.0 \%$ in the UAE in 2017, but these figures are predicted to rise to $31.7 \%$ and $30.2 \%$, respectively, by 2030. The number of common cases of NAFLDrelated compensated cirrhosis was projected to increase by $262 \%$ in Saudi Arabia from 2017 to 2030 and by $232 \%$ in the UAE by 2030 . For NASH, the prevalence rate of NAFLD in Saudi Arabia was estimated to reach $4.2 \%$ in 2017 , and $4.1 \%$ in the UAE. The number of NASH cases is expected to increase by $6.8 \%$ in Saudi Arabia by 2030 ; as for the UAE, the cases have increased by $6.4 \%(9)$.

\section{Viral Hepatitis Prevalence Rates}

Two types of viral hepatitis are the most common in the GCC member countries. The first is hepatitis $B$ virus (HBV) infection, which causes hepatitis $B$ disease. In many countries, the virus has been a severe problem, and GCC member countries are no exception. The disease's spread is known to be driven by certain risk factors. Individuals with $\mathrm{CHB}$ have a lifelong risk of developing end-stage liver disease, including cirrhosis, liver failure, and liver cancer (10). In addition to its effect on people's lives, HBV infection drains the health system's resources because of the cost of the treatment for liver cirrhosis and HCC, which may result from HBV. Furthermore, the health-related quality of life of patients with $\mathrm{CHB}$ tends to be impaired during the later stages of liver disease.

A systematic review study found that approximately $35 \%$ of Saudi Arabia's HCC cases were related to 
HBV (11). Another recent study from the Systematic Observatory Liver Disease Registry, which collects data from several centers across the country and from the Liver Disease Research Center of the King Saud University Medical City, analyzed the 2010 and 2015 HBV-infected cohorts and concluded that compared to the 2010 cohort, the 2015 cohort was not only significantly older but was more likely to have liver disease sequelae, such as HCC (1\% vs. $12 \%)$ and cirrhosis ( $5 \%$ vs. $23 \%)$, as well as other comorbidities, such as coronary artery disease $(4 \%$ vs. $10 \%)(12)$.

Hepatitis $C$ is the other common type of viral hepatitis in GCC member countries. Infection with the hepatitis $C$ virus $(\mathrm{HCV})$ is a significant cause of chronic hepatitis, cirrhosis, and HCC and is the world's leading liver transplantation indication. Seven HCV genotypes have been identified based on the results of phylogenetic and sequencing analysis of the HCV genome. GT1 has the highest regional distribution in the Americas, Europe, Asia, and Australasia, but GT4 predominates in the Middle East, North Africa, and Central and Eastern Sub-Saharan Africa (13). The aim of the treatment of people with chronic hepatitis $\mathrm{C}$ is to eliminate the virus, further reducing the risk of all-cause and liver-related deaths, the need for liver transplant, disease progression to $\mathrm{HCC}$, and liver complications. Treatment protocols for HCV infection have significantly advanced in the past years as a consequence of the availability of recent highly effective, oral, direct-acting antiviral (DAA) medications (14). This treatment modality has produced exceptional cure rates, with a sustained virologic response (SVR) exceeding $90 \%$, in addition to its other advantages, such as: tolerability, reduced of side effects, and the short period of therapy (15).
Despite the variability in the prevalence rate of $\mathrm{HCV}$ in the GCC member countries, the overall prevalence rates are close to the global prevalence rate. The prevalence rate of $\mathrm{HCV}$ among nationals tends to be approximately $1 \%$ and is usually lower among resident expatriates. The high prevalence rate of $\mathrm{HCV}$ observed, in particular in expatriate populations, seems to reflect the higher prevalence rate of HCV in their country of origin. Continuous transmission tends to be concentrated in high-risk populations and is associated with medical care. Drug injection may be a major contributor to the incidence of $\mathrm{HCV}$ in this area but is unlikely to explain more than a minority of the prevalent infections (16).

\section{Liver Cancer}

Cancer involves abnormal tissue development in an organ in the body. Hepatic cancer is a form of cancer that affects the largest abdominal organ: the liver. Hepatic cancer is divided into two categories: primary liver cancer and secondary liver cancer. Primary liver cancer originates in the liver itself and is recognized as the most common form of HCC. Secondary liver cancer is a form of cancer cell growth in which the cancer cell originates from different organs and spreads to the liver (17). Liver cancer is considered the third most common malignancy among males and the seventh among females worldwide, with more than 800,000 new cases diagnosed every year (18). Well-known risk factors for HCC include chronic infection with HBV, which is considered the most critical risk factor for $\mathrm{HCC}$ in several countries in Asia and Africa, and HCV, which was found to be the most critical risk factor for HCC in the Western countries.

Table 1: Summary of Liver Status

\begin{tabular}{|c|c|c|c|c|c|c|}
\hline & $\begin{array}{c}\text { Start of } \\
\text { Vaccination } \\
\text { Program } \\
\text { Implementati } \\
\text { on (Year) }\end{array}$ & $\begin{array}{c}\text { Hepatitis B } \\
\text { Virus HBV } \\
\text { Prevalence } \\
\text { Rate }\end{array}$ & $\begin{array}{c}\text { Hepatitis C } \\
\text { Virus HCV } \\
\text { Prevalence } \\
\text { Rate }\end{array}$ & $\begin{array}{l}\text { Start of Liver } \\
\text { Transplantatio } \\
\text { ns Program } \\
\text { Implementatio } \\
\text { n (Year) }\end{array}$ & $\begin{array}{l}\text { Non-Alcoholic } \\
\text { Fatty Liver } \\
\text { Disease } \\
\text { NAFLD } \\
\text { Prevalence } \\
\text { Rate \% (2017) }\end{array}$ & $\begin{array}{c}\text { Non-Alcoholic } \\
\text { Fatty Liver } \\
\text { Disease } \\
\text { NAFLD } \\
\text { Prevalence } \\
\text { Rate\% (2030) }\end{array}$ \\
\hline KSA & 1989 & $1.3 \%$ & $0.3 \%$ & 1990 & $25.7 \%$ & $31.7 \%$ \\
\hline UAE & 1991 & * & $1.3 \%$ & 2007 & $25.0 \%$ & $30.2 \%$ \\
\hline Bahrain & 1997 & $0.58 \%$ & $1.2 \%$ & * & * & * \\
\hline Qatar & 1989 & 0 & $1.6 \%$ & 2011 & * & * \\
\hline Kuwait & 1990 & $1 \%$ & * & 2010 & * & * \\
\hline Oman & 1990 & $5.8 \%$ & $0.4 \%$ & 2017 & * & * \\
\hline
\end{tabular}

* Unavailable in the literature searched 
Other risk factors for HCC, include obesity, NAFLD, diabetes, heavy alcohol use, and tobacco smoking (19). HCC's clinical presentation may vary from asymptomatic to right-upper-quadrant pain, lethargy, jaundice, and weight loss (19).

In 2014, the Saudi Cancer Registry announced that liver cancer ranked sixth among Saudi males and ninth among Saudi females in terms of cancer incidence (20). For example, the registered ASIRs in 2018 for Bahrain, Qatar, the UAE, and Oman (3.4, $4.1,4.2$, and 4.4, respectively) were lower than for Saudi Arabia (21). A recent study revealed a slight increase in the crude incidence rate and ASIR of liver cancer in the Saudi population. Riyadh and Najran reported the highest overall ASIRs of liver cancer among males in the eastern region of Riyadh, and among Saudi females. In contrast, the northern region of Saudi Arabia (Baha and Jazan) had the lowest ASIRs among Saudi males and females. The overall ASIR between 2004 and 2014 per 100,000 males was approximately more than double that of the Saudi female population (22). Another study by Sharafi and Alavian reported that Qatar had the highest liver cancer mortality rate among GCC member countries in 1900 and 2017 (23).

There are several options for treating HCC. The optimal treatment depends on how far the cancer has spread at diagnosis (stage), underlying liver function, and the patient's general health. HCC-patient care can include a surgeon, a cancer specialist (oncologist), a liver specialist (hepatologist), an interventional radiologist, and a PC specialist (24). Despite advancements in medicine, hepatic cancer appears to be one of the most challenging diseases to treat. Surgery, local toxic treatments, and hepatic transplantation have a curative potential for early HCC (25).

An overview of the HBV and HCV prevalence rates in the GCC member countries reflects the variation in each country's healthcare services. This variation empathizes that significant improvements are needed to monitor and control disease spread. Understanding the importance of liver transplantation, GCC member countries began to offer this treatment early. Saudi Arabia and Qatar performed the first liver transplantation in the Gulf region in 1990, and they were followed by the other countries. It has been estimated that the prevalence rate of NAFLD in the region will increase from 2017 to 2030. In the Gulf countries, the burden of NAFLD-related liver disease is expected to reach very high levels by 2030 . A summary of liver diseases status of the GCC countries is presented in Table 1.

\section{METHODS}

This study was conducted as a comparative systematic review of the literature on the current status of liver disease in GCC member countries. An online search was carried out to obtain an overview of clinical healthcare services, and of the current status of liver diseases in these countries. A list of clinical healthcare services available to people with liver disease in the GCC member countries was created. Then a search was conducted in Google Scholar and the Saudi Digital Library to identify all relevant articles, using the following keywords in the searching strategy: healthcare services for liver patients, liver diseases, liver disease patients, hepatitis B, hepatitis $C$, liver cancer, fatty liver disease, mental health support for liver disease patients, liver PC, liver surgery, liver transplantation, management of viral hepatitis $B$ and $C$, dental care services for liver disease patients, HBV and pregnancy, vaccination among $\mathrm{HCWs}$ and national screening, Arabian Gulf, GCC Saudi Arabia, Kuwait, and United Arab Emirates, Oman, Qatar, and Bahrain. The type of clinical healthcare service was linked to each specific GCC member country using the Boolean operator 'AND'. Among research articles focusing on healthcare services in GCC member countries, only those published in English were included in the study.

\section{Inclusion Criteria}

Articles were selected according to the following inclusion criteria:

Studies conducted from 2014 to 2020 and published in international or local journals were included in this study. Once exception was a study carried out in Saudi Arabia in 2012 as it was the latest article describing the HBV vaccination implementation program in Saudi Arabia.

Articles relevant to the study topic (those reporting liver disease prevalence rate, incidence, and clinical healthcare services, including mental health support, PC, liver surgery and transplantation, management of viral hepatitis $B$ and $C$, dental care services, HBV and pregnancy, vaccination among HCWs and national screening) were included in this study.

Studies that reviewed the official websites of the Gulf Ministries of Health, the Gulf Cooperation Council, and other official websites were included in this study. 


\section{Exclusion Criteria}

Articles were excluded according to the following exclusion criteria:

Articles not related to the study topic (excluded in the early stages of the titles and abstracts screening) were excluded from this study.

Duplicate articles were excluded for this study.

Articles pertaining to a population outside the GCC region were excluded from this study.

\section{Review Selection and Data Extraction}

The proliferation of web-based technologies aided in the collection of the available data. The full-text articles of relevant titles/abstracts were accessed through Google Scholar, which covers all subject areas and involves different types of reference (e.g., conferences, reports, books) that cannot be found in the Web of Science or PubMed and whose results can be sorted by date. Those that were not freely available in Google Scholar were obtained through the Saudi Digital Library, which has among the largest collection of electronic books in the Arab region. Partnering with reputable publishers including, but not limited to, Oxford University Press, Harvard University, Taylor and Francis, Springer, and Elsevier, the Saudi Digital Library infrastructure project is strategically positioned to ensure ease of access to quality data, which is important in the compilation of research materials. As the evaluated outcomes of this systematic review encompass a wide variety of characteristics and involve different countries, the reviewed articles were divided into two groups: (1) those that addressed the current status of liver disease, which was relevant to the first objective of the study; and (2) those that addressed clinical healthcare services in GCC member countries, which was relevant to the second objective of the study. The initial selection criteria were broad to ensure that as many studies as possible were assessed based on their relevance to the review. The titles were screened, and the abstracts of 117 articles were identified for relevance. Whether the complete text could be retrieved for comparing a study's inclusion/exclusion criteria with those of this review was also determine, and those criteria were used to decide whether the paper could be included in the review. After removing duplicates and screening for eligibility, the resulting articles numbered 96 . Of these, 29 articles were selected for the review of the current status of liver disease patients in the GCC member countries, and 19 articles were targeted to be used for assessing clinical care services for liver disease patients in such countries (Figure 1); these articles are presented in Table 2. The search results were further screened, and the extracted data were gathered to compare clinical healthcare services for liver disease patients in the GCC member countries in this review.

\section{Ethical Statement}

The authors are accountable for all aspects of the work in ensuring that questions related to the accuracy or integrity of any part of the work are appropriately investigated and resolved.

\section{RESULTS}

This systematic review showed that most clinical healthcare services can be easily accessed by liver disease patients in GCC member countries, as shown in Table 3. Much effort and many strategies have been used to manage both communicable diseases and NCDs in GCC member countries. The communicable-disease prevalence rate significantly decreed by all the countries is effectively monitored by healthcare systems to control disease spread at the GCC level. Despite their decrease in prevalence, NCDs will remain a considerable burden for the GCC healthcare system for years to come, and additional challenges are anticipated. Furthermore, a large number of undiagnosed cases continue to be diagnosed at advanced stage of liver disease.

The GCC countries exhibited similarities in their management of viral hepatitis by treating infected people with medicines, preventing others from becoming infected through vaccination, and controlling transmission in the community through the premarital screening program. All the GCC ministries of health have now made anti-HBV vaccination compulsory before one can be hired. These policies play a significant role in avoiding the financial, psychological, and social burdens present in populations affected by infectious diseases. By contrast, there was a difference in the availability of liver transplantation program among GCC member countries, namely, this program was not available in Bahrain and the UAE. In addition, there was a difference in PC levels in GCC countries, stemming from the availability of care in primary hospitals to specialized centers. 
Table 2: Selected studies for analysis

\begin{tabular}{|c|c|c|c|c|}
\hline No. & Title of Article & $\begin{array}{l}\text { Publication } \\
\text { Year }\end{array}$ & Country & Author(s) \\
\hline 1 & $\begin{array}{l}\text { National screening programs in Saudi } \\
\text { Arabia: Overview, outcomes, and } \\
\text { effectiveness }\end{array}$ & 2019 & $\begin{array}{l}\text { Saudi } \\
\text { Arabia }\end{array}$ & Gosadi IM. (26) \\
\hline 2 & $\begin{array}{l}\text { Epidemiology of viral hepatitis in } \\
\text { Saudi Arabia: Are we off the hook? }\end{array}$ & 2012 & $\begin{array}{l}\text { Saudi } \\
\text { Arabia }\end{array}$ & Abdo AA, Sanai FM, Al-Faleh FZ. (27) \\
\hline 3 & $\begin{array}{l}\text { Hepatitis B vaccination coverage and } \\
\text { knowledge among healthcare } \\
\text { workers at a tertiary hospital in } \\
\text { Jeddah, Saudi Arabia }\end{array}$ & 2016 & $\begin{array}{l}\text { Saudi } \\
\text { Arabia }\end{array}$ & Hegazy A, Albar HM, Albar NH. (28) \\
\hline 4 & $\begin{array}{l}\text { Willingness of Saudi dental } \\
\text { professionals to treat hepatitis B } \\
\text { virus-infected patients }\end{array}$ & 2015 & $\begin{array}{l}\text { Saudi } \\
\text { Arabia }\end{array}$ & Khalil H. (29) \\
\hline 5 & $\begin{array}{l}\text { SASLT practice guidelines for the } \\
\text { management of hepatitis B virus }\end{array}$ & 2014 & $\begin{array}{l}\text { Saudi } \\
\text { Arabia }\end{array}$ & $\begin{array}{l}\text { Abaalkhail F, Elsiesy H, AlOmair A, et } \\
\text { al. (30) }\end{array}$ \\
\hline 6 & $\begin{array}{l}\text { HCV burden and barriers to } \\
\text { elimination in the Middle East }\end{array}$ & 2019 & $\begin{array}{l}\text { All GCC } \\
\text { countries }\end{array}$ & Blach S, Sanai FM. (43) \\
\hline 7 & $\begin{array}{l}\text { Liver transplantation in the Kingdom } \\
\text { of Saudi Arabia }\end{array}$ & 2017 & $\begin{array}{l}\text { Saudi } \\
\text { Arabia }\end{array}$ & $\begin{array}{l}\text { Al Sebayel M, Abaalkhail F, Al Abbad } \\
\text { S, et al. (31) }\end{array}$ \\
\hline 8 & $\begin{array}{l}\text { Prevalence and severity of pain in } \\
\text { cancer patients in an outpatient } \\
\text { palliative care setting in Saudi Arabia }\end{array}$ & 2014 & $\begin{array}{l}\text { Saudi } \\
\text { Arabia }\end{array}$ & $\begin{array}{l}\text { Al-Zahrani O, Eldali A, Al-Shahri MZ. } \\
\text { (32) }\end{array}$ \\
\hline 9 & $\begin{array}{l}\text { Hepatitis B care pathway in the } \\
\text { United Arab Emirates: Current } \\
\text { situation, gaps, and actions }\end{array}$ & 2019 & $\begin{array}{l}\text { United } \\
\text { Arab } \\
\text { Emirates }\end{array}$ & $\begin{array}{l}\text { Al Zaabi M, Al Quraishi H, Al Rifai A, } \\
\text { et al. (33) }\end{array}$ \\
\hline 10 & $\begin{array}{l}\text { Status of liver transplantation in the } \\
\text { Arab world }\end{array}$ & 2014 & $\begin{array}{l}\text { All GCC } \\
\text { countries }\end{array}$ & $\begin{array}{l}\text { Khalaf H, Marwan I, Al-Sebayel M, et } \\
\text { al. (34) }\end{array}$ \\
\hline 11 & $\begin{array}{l}\text { Prevalence and risk factors of } \\
\text { hepatitis B virus infection in Bahrain, } \\
2000 \text { through } 2010\end{array}$ & 2014 & Bahrain & Janahi EM. (39) \\
\hline 12 & $\begin{array}{l}\text { Historical epidemiology of hepatitis C } \\
\text { virus in select countries }\end{array}$ & 2017 & $\begin{array}{l}\text { All GCC } \\
\text { countries }\end{array}$ & $\begin{array}{l}\text { Maaroufi, A, Vince, A, Himatt, SM, et } \\
\text { al. (40) }\end{array}$ \\
\hline 13 & $\begin{array}{l}\text { Demographics and epidemiology of } \\
\text { hepatitis B in the state of Qatar: A } \\
\text { five-year surveillance-based } \\
\text { incidence study }\end{array}$ & 2019 & Qatar & $\begin{array}{l}\text { Al Romaihi HE, Ganesan N, Farag } \\
\text { EA, et al. (35) }\end{array}$ \\
\hline 14 & $\begin{array}{l}\text { Assessment of hepatitis B } \\
\text { immunization programme among } \\
\text { school students in Qatar }\end{array}$ & 2018 & Qatar & $\begin{array}{l}\text { Al-Romaihi H, Al-Masri H, Shawky S, } \\
\text { at el. (36) }\end{array}$ \\
\hline 15 & $\begin{array}{l}\text { Seroprotection against vaccine- } \\
\text { preventable diseases amongst health } \\
\text { care workers in a community hospital, } \\
\text { Qatar }\end{array}$ & 2016 & Qatar & $\begin{array}{l}\text { Guanche Garcell H, Villanueva Arias } \\
\text { A, Guilarte García E, et al. (37) }\end{array}$ \\
\hline 16 & $\begin{array}{l}\text { The role of palliative care in the } \\
\text { management of patients with } \\
\text { advanced hepatocellular carcinoma: } \\
\text { A single institution experience }\end{array}$ & 2016 & Qatar & $\begin{array}{l}\text { Ayman A, Azza AH, Yasser K, et al. } \\
\text { (38) }\end{array}$ \\
\hline 17 & $\begin{array}{l}\text { Timing and outcome of referral to the } \\
\text { first stand-alone palliative care center } \\
\text { in the Eastern Mediterranean Region, } \\
\text { the Palliative Care Center of Kuwait }\end{array}$ & 2017 & Kuwait & $\begin{array}{l}\text { Al-Saleh K, Al-Awadi A, Soliman NA, } \\
\text { et al. (41) }\end{array}$ \\
\hline 18 & $\begin{array}{l}\text { Molecular epidemiology and } \\
\text { genotyping of hepatitis B virus of } \\
\text { HBsAg-positive patients in Oman }\end{array}$ & 2014 & Oman & $\begin{array}{l}\text { Al Baqlani SA, Sy BT, Ratsch BA, et } \\
\text { al. (42) }\end{array}$ \\
\hline 19 & $\begin{array}{l}\text { Barriers to, and opportunities for, } \\
\text { palliative care development in the } \\
\text { Eastern Mediterranean Region }\end{array}$ & 2017 & Oman & Fadhil I, Lyons G, Payne S. (43) \\
\hline
\end{tabular}


Table 3: Clinical healthcare services available for liver disease patients in the searched literature

\begin{tabular}{l|l|l|l|l|l|l|l|}
\hline$\#$ & $\begin{array}{l}\text { Clinical } \\
\text { Services }\end{array}$ & KSA & UAE & Bahrain & Qatar & Kuwait & Oman \\
\hline 1 & National screening & $\checkmark$ & $\checkmark$ & $\checkmark$ & $\checkmark$ & $\checkmark$ & $\checkmark$ \\
\hline 2 & $\begin{array}{l}\text { Hepatitis B Virus HBV vaccination } \\
\text { program }\end{array}$ & $\checkmark$ & $\checkmark$ & $\checkmark$ & $\checkmark$ & $\checkmark$ & $\checkmark$ \\
\hline 3 & $\begin{array}{l}\text { Healthcare workers Hepatitis B } \\
\text { Virus HCWs HBV vaccination } \\
\text { program }\end{array}$ & $\checkmark$ & $\checkmark$ & $\checkmark$ & $\checkmark$ & $\checkmark$ & $\checkmark$ \\
\hline 4 & Dental care service & $\checkmark$ & X & X & X & X & X \\
\hline 5 & $\begin{array}{l}\text { Hepatitis B Virus HBV and } \\
\text { pregnancy guidelines }\end{array}$ & $\checkmark$ & X & X & X & X & X \\
\hline 6 & Hepatitis C Virus HCV Treatment & $\checkmark$ & $\checkmark$ & $\checkmark$ & $\checkmark$ & $\checkmark$ & $\checkmark$ \\
\hline 7 & Liver Transplantation & $\checkmark$ & X & $\checkmark$ & $\checkmark$ & $X$ & $X$ \\
\hline 8 & Mental health program & $\checkmark$ & X & X & X & X & X \\
\hline 9 & Palliative Care PC & $\checkmark$ & $\checkmark$ & $\checkmark$ & $\checkmark$ & $\checkmark$ & $\checkmark$ \\
\hline
\end{tabular}

\section{DISCUSSION}

This systematic review showed that in the GCC member countries, most clinical healthcare services can be easily accessed by liver disease patients, as shown in Table 1. The communicable-disease prevalence rate significantly decreed by all the countries is effectively monitored by healthcare systems to control the spread of disease at the GCC level. Much effort and many strategies have been used to manage NCDs in the GCC member countries.

\section{Saudi Arabia}

According to the Saudi Ministry of Health (MOH), 75\% of the Saudi population do not undergo routine checkups, $60 \%$ are either overweight or obese, $60 \%$ do not perform enough physical exercise, and $18 \%$ are

Figure 1. Publication selection process

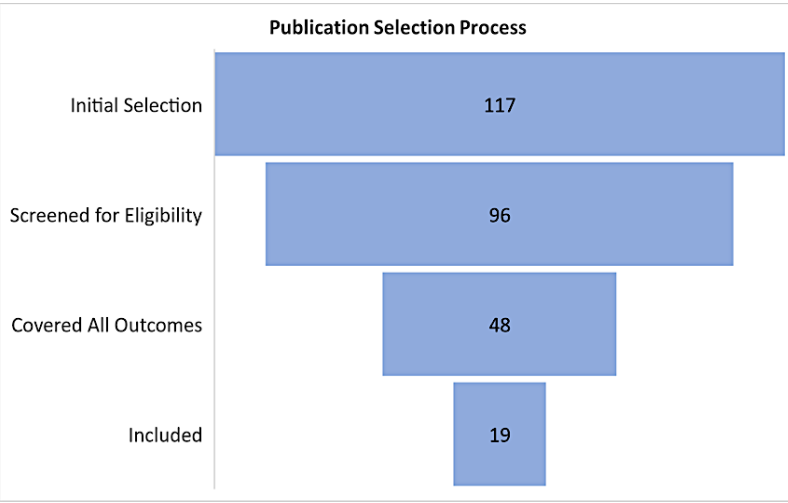

smokers. In addition to other government health services, there is a national premarital screening program exclusively provided by the Saudi $\mathrm{MOH}$. The program is implemented across the country, and includes specific explanations of targeted subjects, screening test locations, and the screening process (26).

In the past 30 years, Saudi Arabia has experienced a steady decrease in HBV prevalence. This decrease can be attributed to improved living conditions in the country, HBV immunization of infants, compulsory blood bank screening, and increased awareness of healthy clinical and social practices. Despite declined prevalence, chronic liver disease will remain a considerable burden for the Saudi healthcare system for years to come, and additional challenges are anticipated. A large number of undiagnosed cases continue to be diagnosed at advanced stage of the disease. The percentage of patients with liver cirrhosis who experience complications and need specialized care will increase over the next 20-40 years. A significant objective is an initiative that involves early identification, proper and prompt assessment, and successful treatment. A more organized national initiative that entails increasing the availability of liver transplantation for patients with end-stage liver disorders will be needed to achieve this objective. Since the introduction of the national vaccination program, three follow-up studies have been carried out to track HBV's prevalence rate in Saudi children over the past two decades. All the 
studies reported a substantial decrease in HBsAg prevalence to negligible numbers, confirming that the HBV vaccine was highly successful (27).

Although most hospitals in the country have policies that require their staff to be vaccinated against HBV, and although all staff in the hospital are regularly eligible for free HBV vaccination, the coverage of hepatitis $B$ vaccination among HCWs in the hospitals was low. The hospitals lack an understanding of some assumptions regarding the vaccine for HBV, even if they had a strong awareness of existence of the vaccine (28).

Many dentists in Saudi Arabia have been vaccinated against HBV. Dentists should be vaccinated against HBV because unvaccinated dentists are five times more likely to become infected with the virus than vaccinated dentists. However, this study showed that $89.8 \%$ of dentists in Saudi Arabia are unwilling to treat HBV-infected patients due to the fear of crossinfection. The high percentage of Saudi dentists who are reluctant to treat HBV-infected patients may encourage the patients not to reveal their infection status in their medical history unless dentists' attitudes change. However, while refusing to treat HBV-infected patients in Saudi Arabia is unacceptable, the dentists who refuse to treat such patients cannot be forced to treat them. As mentioned earlier, this practice mainly arises due to concern about the risk of cross-infection. This fear of the dentists may occur because despite the high percentage of Saudi dentists who have been vaccinated against $\mathrm{HBV}$, many of them not been tested for HBV antibody levels. All vaccinated dentists should closely monitor their antibody levels to determine their need for booster vaccination. There is also a need for an educational program to improve the dentists' behavior toward treating HBV-infected patients, and patients who have been infected with blood-borne viruses. It is also recommended that all dentists use the universal precaution system in treating patients, whether or not they have been infected with HBV (29).

A detailed local guideline was created to unify the practice of HBV treatment in Saudi Arabia. Practice guidelines were developed to assist healthcare providers in the management of HBV. Additionally, the guidelines summarize the major studies that have been conducted on HBV epidemiology in Saudi Arabia to emphasize the significant changes in this virus's prevalence in the region. The grading system summary of recommendations was based on the best available evidence that applies to Saudi patients. This system was adopted from major international practice guidelines on the management of HBV (30).

In the last three decades, Saudi Arabia's liver transplantation expertise has grown dramatically. LDLT has helped mitigate the organ shortage crisis to some extent. However, significant efforts need to be made to meet the increasing need for liver transplantation in Saudi Arabia, especially the promotion of cadaveric donation (31).

$\mathrm{PC}$ is available in only a few of the many tertiary hospitals in Saudi Arabia that treat cancer patients. Recognizing the shortage of skilled PC workers worldwide, it was proposed that a national Saudi PC program be established, using the King Faisal Specialist Hospital and Research Center in Riyadh as a training center and as a source of support to the other healthcare institutions throughout the country, considering the hospital experience as the first PC program in the country in the early 1990s (32).

\section{United Arab Emirates}

Over the past 30 years, the UAE has made substantial progress in controlling HBV prevalence in the country through its national vaccination program. However, issues remain in CHB management and long-term disease follow-up. There are many mandatory screening frameworks present in the country that classify patients via blood tests (HBsAg test, blood donor antibodies), but national screening is not available. Patients in the public sector (Emiratis only) and in the private sector (Emiratis and expatriates) receive antiviral care. The major disadvantage of current antiviral therapy is that in a situation in which lifelong treatment may be necessary, the long-term toxicity and health consequences are uncertain. A treatment that can cure HBV is currently a significant unmet need. There is also an unmet need for new successful treatment options in the absence of such curative therapy, with a higher barrier to resistance and fewer treatmentrelated adverse outcomes than the currently available treatment options. Noncompliance with the recommended follow-up appointments is a significant obstacle to the completion of care and is often related to adverse health results. UAE experts consider compliance with and adherence to care among Emirati patients high: approximately $80-90 \%$ of patients starting treatment remain compliant. There are no local guidelines for HBV; therefore, most specialists follow the guidelines of the European 
Association for the Study of Liver (33). Some liver transplantations have been conducted by the initial liver transplantation programs in the UAE but were subsequently discontinued for logistical and technical reasons (34).

\section{Qatar}

Qatar has developed several infectious-disease programs, including an HBV detection and control program. The decreasing morbidity of infections in Qatar's population might be due to the increase in preventive measures, including immunization, blood donation screening, maternal and premarital screening, and education about and understanding of public health (35). Primary healthcare centers across the country provide all children, regardless of ethnicity, free hepatitis $B$ vaccinations. Vaccines are also provided to all children born in hospitals. Highquality vaccine management is in place to address shortages and to ensure availability for all children. The Department of Health Protection and Communicable Diseases in the Ministry of Public Health has a tracking system that counts the number of children requiring vaccination to ensure coverage. A follow-up study was conducted to measure the effect of the HBV vaccination program on achieving high vaccine coverage in the country at both the national and regional levels, and $100 \%$ coverage was achieved among Qatari children. Indeed, the healthrelated needs and activities of children cannot be ignored. Children from different countries can have different health needs, and different cultural norms and practices may alter the risk of HBV transmission (36).

$\mathrm{HCW}$ are at high risk of acquiring several infectious diseases and can transmit infections in healthcare facilities, leading to a dual risk. The coverage of hepatitis $B$ vaccination and the prevalence of the nonimmune personnel among the HCWs who were examined were acceptable. The deficiency in vaccination coverage was attributed to several factors, including refusal to submit to vaccination due to fear of adverse events, low risk perception, doubt about vaccination efficacy and the availability of freeof-charge services, etc. Compared to physicians and technicians, nurses (mostly females) have higher hepatitis $B$ vaccination coverage, which is most likely due to individual influences (e.g., risk perception) or the more significant emphasis on vaccination services for particular occupational categories.
Similarly, increased coverage among older HCWs may reflect vaccination program success (37).

Patients with advanced HCC are accepted by the PC program at the Qatar National Center for Cancer Care and Research. The symptoms of these patients have a detrimental effect on quality of life and functional status. Treatment of patients with advanced HCC only addresses the symptoms, and no definitive tumor-directed therapy is indicated. These patients should obtain only palliative supportive treatment to try to improve their quality of life and to maximize their symptom control. Efforts have been exerted and strategies have been devised to improve PC services for patients with an advanced cancer diagnosis in the state of Qatar (38).

\section{Bahrain}

The first research analysis of HBV infections conducted in Bahrain indicated that the country has had low HBV endemicity for the last 10 years (2000-2010) (39). This shift might be partly due to the 1992 implementation of the national HBV vaccination program for neonates and adult risk groups, such as health professionals. Nationality was a significant variable that affected the prevalence, as the percentage of non-Bahraini citizens increased to $54 \%$ in 2010 from $38 \%$ in 2001 . The risk of infection was almost twice as high in non-Bahraini citizens than Bahrainis citizens. Similar results were observed in a study conducted in the eastern region of Saudi Arabia, where the prevalence rate was significantly higher $(24.73 \%$ vs. $13.53 \%)$ in non-Saudi blood donors versus Saudi blood donors. The majority of non-Bahraini patients were citizens of six countries, namely, India, Pakistan, Bangladesh, the Philippines, Indonesia, and Ethiopia, which are highly endemic for HBV. HBV is a significant public health problem in both rural and urban areas of the Indian subcontinent. This is in consistent with the fact that citizens of these countries make up most of the expatriate population in Bahrain. Infected workers living abroad are the leading cause of hepatitis B transmission to other countries; in addition, such workers participate in practices that put them at a higher risk of contracting hepatitis $B$. Most workers from these countries that are highly endemic for hepatitis $B$ have low education and socioeconomic backgrounds, and these workers contribute to disease transmission as they tend to live in small, crowded houses with their nuclear and extended families and therefore live in close proximity 
with these family members; thus, these people engage in activities that may put them at a greater risk of contracting HBV, such as sharing personal items with the other members of their household.

Expatriates/immigrants also play a critical role in current hepatitis B epidemiology in Bahrain. The invariable prevalence of HBV infection in the country over the past 10 years may reflect the steady increase in the population during that period, despite the rise in the actual number of positive patients. In addition, recognizing the diversity of the community will lead to significant advancement of HBV prevention and control programs. The country still does not have a local transplantation program available, but patients receive transplantations

through collaborations with transplantation centers abroad (40).

\section{Kuwait}

Kuwait initially conducted a few liver transplantations, but these were subsequently discontinued due to logistical and technological reasons (34). The country took the lead and started standalone PC models in the Eastern Mediterranean Regional Office. It was essential to explore the pattern and outcome of referrals to these newly introduced models. Patients with advanced cancer are frequently referred to $P C$ late in the course of disease. More than half $(58 \%)$ of patients were referred to $\mathrm{PC}$ during the last month of their life. The referral was too late for $5 \%$ of the patients who died before the PCC-K consultation team's assessment. Late referral to PC might be due to factors related to healthcare professionals, patients, informal caregivers, the disease itself, and socioeconomic status (41).

\section{Oman}

Oman, a country with intermediate HBV carrier prevalence rate of $2-7 \%$, introduced free HBV vaccination for all newborns in the country in 1990; these vaccines were offered to newborns born to the native and immigrant populations. The effect on vaccination efficacy and coverage was analyzed in a national study in 2005, and this study showed that 15 years after the initiation of newborn HBV vaccination, the prevalence of $\mathrm{CHB}$ in children decreased from $2.3 \%$ in 1990 to $0.5 \%$ in 2005 . Mutation analysis of the HBV isolates revealed a low prevalence of vaccine escape mutants in HBsAg-positive patients, indicating the efficacy of the HBV vaccination program in Oman (42). PC is also in its early developmental stages in Oman. At the main hospital in Muscat, the medical oncology department currently offers critical PC services for terminally ill patients. However, these services are mostly delivered on a day-care basis (43).

Furthermore, the 69th World Health Assembly in 2016 supported the Global Health Sector Strategy in eliminating viral hepatitis, which is considered a danger to public health. The WHO and GHSS have set impact goals to reduce the chronic incidence of viral hepatitis by $90 \%$ and the mortality of viral hepatitis by $65 \%$ by 2030 . HCV elimination strategies exist across GCC. These strategies include initiatives such as the formulation of HCV elimination plans, the establishment of national databases, the introduction of the all-inclusive awareness program, the implementation of screening strategies, and the implementation of test-and-treat micro elimination programs in high-risk populations. Furthermore, access to inexpensive generic DAAs has been pursued and successfully implemented in national elimination plans in some countries, such as Saudi Arabia, where drug pricing has been considered an obstacle to elimination. In Saudi Arabia, Qatar, UAE, and Kuwait, the national strategy implementation is either in progress or in place. Eliminating HCV has been indicated to be not only cost-effective but also cost-saving in GCC member countries. The 2030 deadline is an optimistic target for creating momentum toward a shared purpose, and the advantages of accomplishing this goal will be enjoyed for decades to follow (44).

The GCC countries are similar in the way they manage viral hepatitis: by treating infected people with medicines, preventing others from becoming infected through vaccination, and by controlling transmission in the community through the premarital screening program. All the GCC ministries of health have now made anti-HBV vaccination compulsory before one can be hired. These policies play a significant role in avoiding the financial, psychological, and social burdens that are usually present in populations affected by infectious diseases. In contrast, there is a difference in the liver transplantation program available in the GCC member countries, namely, they are not available in Bahrain or the UAE. In addition, there is a difference in the levels of PC in the GCC countries, from the availability of care in primary hospitals to that in specialized centers. 
One of the healthcare system challenges in the region is the high percentage of residents in the GCC region. The Gulf Health Council responded to this issue by establishing the Expatriates Check Program to ensure that incoming expatriates or residents are free from infectious diseases that may pose a health and security risk to the GCC member countries. The program covers 11 countries, and under the supervision of the Gulf Health Council, incoming expatriate workers are examined in their respective countries before they are given a work visa in any GCC state. The certified centers are committed to implementing the GCC Electronic Link System for the GCC Expatriates Health Check-up Program. The program connects the authorized centers to the Gulf Health Council, the Ministries of Health, the embassies of the GCC member countries, and other important authorities; this program creates a system whereby before visas are issued, the authenticity of the certificates presented by the job applicants, their health records, and other application documents are verified, and visas can be issued quickly while guaranteeing disease-free entry (45). In this review, there was difficulty in finding information related to nonclinical health care for liver disease patients in the GCC member countries.

\section{CONCLUSION}

This research was undertaken to review the current status of liver disease patients in the GCC member countries, to assess clinical care services available to liver disease patients in these countries, and to review the impact of liver disease on the GCC member countries' healthcare systems. The study has shown that most necessary clinical healthcare services are available in the GCC member countries, and some services are also provided between the countries. The prevalence rate of viral hepatitis might be different among countries to another in this region. The GCC member countries' effective management of communicable diseases has decreased the prevalence, incidence, and mortality rates of infectious diseases. On the other hand, NAFLD and related liver diseases may become a burden for the GCC healthcare system.

Based on the research findings, the following recommendations have been made: (1) further research needs to be undertaken to examine the current status of NAFLD and NASH in the GCC member countries as their prevalence rate is predicted to increase in the coming years; (2) further research needs to be undertaken to examine the regional differences in the status of liver diseases in Saudi Arabia and Oman; (3) unified GCC liver guidelines should be established to standardize the clinical healthcare services available to liver disease patients in the region; (4) further research can also be conducted to assess the mental health status of liver disease patients in the GCC member countries; and (5) further research in the nonclinical healthcare services field would be of great help in assessing all healthcare services in the region.

Conflict of Interest: No conflict of interest was declared by the authors.

Peer-review: Externally peer-reviewed.

\section{REFERENCES}

1. World Health Organization. Health systems strengthening glossary; 2011. https://www.who.int/healthsystems/hss_glossar y/en/index5.html

2. Johnson J, Stoskopf C, Shi L. Comparative Health Systems: A Global Perspective. 2nd ed. Burlington, MA: Jones \& Bartlett Learning; 2018.

3. Riegelman R, Kirkwood B. Public health 101: Improving community health. 3rd ed. Burlington, MA: Jones \& Bartlett Learning; 2019.

4. Asrani S, Devarbhavi $\mathrm{H}$, Eaton J, et al. Burden of liver diseases in the world. J Hepatol. 2019;70(1):151-171.

5. Fayadh M. 40 years observation in liver diseases in the Middle East., $J$ Liver. 2016;5(3):48.

6. Younossi Z, Koenig A, Abdelatif D, et al. Wymer M. Global epidemiology of nonalcoholic fatty liver disease-Meta-analytic assessment of prevalence, incidence, and outcomes. Hepatology. 2016;64(1):73-84.

7. Szanto $\mathrm{K}, \mathrm{Li} \mathrm{J}$, Cordero $\mathrm{P}$, et al. Ethnic differences and heterogeneity in genetic and metabolic makeup contributing to nonalcoholic fatty liver disease. Diabetes Metab Syndr Obes. 2019;12:357-367.

8. Al Hammadi H, Reilly J. Prevalence of obesity among school-age children and adolescents in the Gulf cooperation council (GCC) states: a systematic review. BMC Obes. 2019,6:3.

9. Alswat K, Aljumah AA, Sanai FM, et al. Nonalcoholic fatty liver disease burden - Saudi Arabia and United Arab Emirates, 2017-2030. Saudi J Gastroenterol. 2018;24(4):211-219. 
10. Ringelhan $\mathrm{M}, \mathrm{O}^{\prime}$ Connor $\mathrm{T}$, Protzer $\mathrm{U}$, et al. The direct and indirect roles of HBV in liver cancer: prospective markers for HCC screening and potential therapeutic targets. J Pathol. 2015;235(2):355-367.

11. Alavian SM, Haghbin $\mathrm{H}$. Relative Importance of Hepatitis B and C Viruses in Hepatocellular Carcinoma in EMRO Countries and the Middle East: A Systematic Review. Hepat Mon. 2016;16(3):e35106.

12. Sanai FM, Alghamdi H, Alswat KA, et al. Greater prevalence of comorbidities with increasing age: Cross-sectional analysis of chronic hepatitis B patients in Saudi Arabia. Saudi J Gastroenterol. 2019;25(3):194-200.

13. Messina JP, Humphreys I, Flaxman A, et al. Global distribution and prevalence of hepatitis $C$ virus genotypes. Hepatology. 2015;61(1):77-87.

14. Aljumah AA, Abaalkhail $\mathrm{F}, \mathrm{Al}-\mathrm{Ashgar} \mathrm{H}$, et al. Epidemiology, disease burden, and treatment strategies of chronic hepatitis $C$ virus infections in Saudi Arabia in the new treatment paradigm shift. Saudi J Gastroenterol. 2016;22(4):269281.

15. Gutierrez JA, Lawitz EJ, Poordad F. Interferonfree, direct-acting antiviral therapy for chronic hepatitis C. J Viral Hepat. 2015;22(11):861-870.

16. Mohamoud YA, Riome S, Abu-Raddad LJ. Epidemiology of hepatitis $C$ virus in the Arabian Gulf countries: Systematic review and metaanalysis of prevalence. Int J Infect Dis. 2016; 46: 116-125.

17. Dutta A, Dubey A. Detection of Liver Cancer using Image Processing Techniques. 2019 International Conference on Communication and Signal Processing (ICCSP). 2019;315-318.

18. Alqahtani $A$, Khan $Z$, Alloghbi $A$, et al. Hepatocellular Carcinoma: Molecular Mechanisms and Targeted Therapies. Medicina (Kaunas). 2019;55(9):526.

19. Dimitroulis D, Damaskos C, Valsami S, et al. From diagnosis to treatment of hepatocellular carcinoma: An epidemic problem for both developed and developing world. World J Gastroenterol. 2017;23(29):5282-5294.

20. Cancer Incidence Report Saudi Arabia 2014. Saudi Health Council Saudi Cancer Registry; 2014.

https://nhic.gov.sa/eServices/Documents/2014. pdf.
21. Global Cancer Observatory. International Agency for Research on Cancer; 2020. https://gco.iarc.fr/.

22. Alghamdi IG, Alghamdi MS. The Incidence Rate of Liver Cancer in Saudi Arabia: An Observational Descriptive Epidemiological Analysis of Data from the Saudi Cancer Registry (2004-2014). Cancer Manag Res. 2020; 12:1101-1111.

23. Sharafi $\mathrm{H}$, Alavian SM. The Rising Threat of Hepatocellular Carcinoma in the Middle East and North Africa Region: Results From Global Burden of Disease Study 2017. Clin Liver Dis. 2020;14(6):219-223.

24. Mokdad AA, Singal AG, Yopp AC. Treatment of Liver Cancer. JAMA. 2016;315(1):100.

25. Liu CY, Chen KF, Chen PJ. Treatment of Liver Cancer. Cold Spring Harb Perspect Med. 2015;5(9):a021535.

26. Gosadi IM. National screening programs in Saudi Arabia: Overview, outcomes, and effectiveness. J Infect Public Health. 2019;12(5):608-614.

27. Abdo AA, Sanai FM, Al-Faleh FZ. Epidemiology of viral hepatitis in Saudi Arabia: are we off the hook? Saudi J Gastroenterol. 2012;18(6):349357.

28. Hegazy A, Albar HM, Albar NH. Hepatitis B Vaccination Coverage and Knowledge Among Healthcare Workers at a Tertiary Hospital in Jeddah, Saudi Arabia. J Adv Med Pharm Sci. 2016;11(1):1-9

29. Khalil $H$. Willingness of Saudi dental professionals to treat Hepatitis B virus-infected patients. Niger J Clin Pract. 2015;18(2):247-250.

30. Abaalkhail F, Elsiesy H, AIOmair A, et al. SASLT practice guidelines for the management of hepatitis B virus. Saudi J Gastroenterol. 2014;20(1):5-25.

31. Al Sebayel M, Abaalkhail F, Al Abbad S, et al. Liver transplantation in the Kingdom of Saudi Arabia. Liver Transpl. 2017;23(10):1312-1317.

32. Al-Zahrani O, Eldali A, Al-Shahri MZ. Prevalence and severity of pain in cancer patients in an outpatient palliative care setting in Saudi Arabia. Qatar Med J. 2014;2014(1):38-45.

33. Al Zaabi $M$, Al Quraishi $H$, Al Rifai $A$, et al. Hepatitis B Care Pathway in the United Arab Emirates: Current Situation, Gaps, and Actions. Eur Med J Hepatol. 2019. 
34. Khalaf H, Marwan I, Al-Sebayel M, et al. Status of liver transplantation in the Arab world. Transplantation. 2014;97(7):722-724.

35. Al Romaihi HE, Ganesan N, Farag EA, et al. Demographics and Epidemiology of Hepatitis B in the State of Qatar: A Five-Year SurveillanceBased Incidence Study. Pathogens. 2019;8(2):68.

36. Al-Romaihi $\mathrm{H}$, Al-Masri $\mathrm{H}$, Shawky $\mathrm{S}$, at el. Assessment of hepatitis B immunization programme among school students in Qatar. East Mediterr Health J. 2018;24(8):736-744.

37. Guanche Garcell H, Villanueva Arias A, Guilarte García E, et al. Seroprotection against VaccinePreventable Diseases amongst Health Care Workers in a Community Hospital, Qatar. Int J Occup Environ Med. 2016;7(4):234-240.

38. Ayman A, Azza AH, Yasser K, et al. The Role of Palliative Care in the Management of Patients with Advanced Hepatocellular Carcinoma: A Single Institution Experience. , J Pat Care. 2016; 2(2):1000112.

39. Janahi EM. Prevalence and Risk Factors of Hepatitis B Virus Infection in Bahrain, 2000 through 2010. PloS One, 2014; 9(2): e87599.

40. Maaroufi, A, Vince, A, Himatt, SM, et al. Historical epidemiology of hepatitis $C$ virus in select countries - volume 4. J Viral Hepat. 2017;24(Suppl. 2):8-24.

41. Al-Saleh K, Al-Awadi A, Soliman NA, et al. Timing and Outcome of Referral to the First Stand-Alone Palliative Care Center in the Eastern Mediterranean Region, the Palliative Care Center of Kuwait. Am J Hosp Palliat Care. 2017;34(4):325-329.

42. Al Baqlani SA, Sy BT, Ratsch BA, et al. Molecular Epidemiology and Genotyping of Hepatitis B Virus of HBsAg-Positive Patients in Oman. PLoS One. 2014;9(5):e97759.

43. Fadhil I, Lyons G, Payne S. Barriers to, and opportunities for, palliative care development in the Eastern Mediterranean Region. Lancet Oncol. 2017;18(3):e176-e184.

44. Blach S, Sanai FM. HCV Burden and Barriers to Elimination in the Middle East. Clin Liver Dis (Hoboken). 2019;14(6):224-227.

45. Al Awaidy ST, Ezzikouri S. Moving towards hepatitis B elimination in Gulf Health Council states: From commitment to action. J Infect Public Health. 2020;13(2):221-227. 